\title{
Ultrasound-Assisted Emulsification Microextraction Based on Solidification Floating Organic Drop Trace Amounts of Manganese Prior to Graphite Furnace Atomic Absorption Spectrometry Determination
}

\author{
Alireza Mohadesi and Masoumeh Falahnejad \\ Department of Chemistry, Payame Noor University, P.O. Box 19395-3697, Tehran, Iran \\ Correspondence should be addressed to Alireza Mohadesi, mohadesi_a@yahoo.com
}

Received 13 January 2012; Accepted 1 February 2012

Academic Editors: H. Filik and J. L. Todoli

Copyright (C) 2012 A. Mohadesi and M. Falahnejad. This is an open access article distributed under the Creative Commons Attribution License, which permits unrestricted use, distribution, and reproduction in any medium, provided the original work is properly cited.

\begin{abstract}
In the present study, an ultrasound-assisted emulsification microextraction based on solidification floating organic drop method is described for preconcentration of trace amounts of Mn (II). 2-(5-Bromo-2-pyridylazo)-5 diethylaminophenol was added to a solution of $\mathrm{Mn}^{+2}$ at $\mathrm{ph}=10.0$. After this, 1-undecanol was added to the solution as an extraction solvent, and solution was stirred. Several factors influencing the microextraction efficiency, such as $\mathrm{pH}$, the amount of chelating agent, nature and volume of extraction solvent, the volume of sample solution, stirring rate, and extraction time were investigated and optimized. Then sample vial was cooled by inserting into an ice bath, and the solidified was transferred into a suitable vial for immediate melting. Finally the sample was injected into a graphite furnace atomic absorption spectrometry. Under the optimum condition the linear dynamic range was $0.50-10.0 \mathrm{ng} \mathrm{mL}^{-1}$ with a correlation coefficient of 0.9926 , and the detection limit of $0.3 \mathrm{ng} \mathrm{mL}^{-1}$ was obtained. The enrichment factor was 160 . The proposed method was successfully applied for separation and determination of manganese in sea, rain, tap, and river water samples.
\end{abstract}

\section{Introduction}

Manganese is recognized as both an essential and a neurotoxic trace element. As an essential trace element, Mn plays an important role in bone and tissue formation, reproductive functions, and the activation of many enzymes, which are involved in vital metabolic processes [1]. Element deficiency is not a common occurrence since dietary sources provide an adequate supply of $2-8 \mathrm{mg}$ of $\mathrm{Mn}$ per day. However, toxic levels may be reached in workers or individuals living near mines, ore-processing plants, or manufactures of varnish, pharmaceutical products, ceramics, and pottery. There is still little information on the biochemical mechanism, which could explain the like symptoms, caused by chronic inhalation of excess levels of Mn [1,2]. Manganese exists mainly in both manganese (II) and manganese (IV) oxidation states in ordinary aqueous environments. In aqueous environments manganese (IV) is a dominant chemical species and exists in insoluble forms, such as particulate and colloidal $\mathrm{MnO}_{2}$. However, manganese (II) ion is rather stable in aqueous environments, which are often linked with water pollution, especially for drinking water $[3,4]$. The greatest parts of dissolved manganese in environmental waters are thought to be manganese (II) ion [5]. The direct determination of trace manganese ions is generally difficult because of matrix interference problems and low concentration of metals in samples. These problems can be overcome by using preconcentration and separation procedures before the detection procedure. For this purpose, various methods for the separation and preconcentration of manganese have been reported, such as solid-phase extraction [6-10], liquidliquid extraction [11], cloud point extraction [12], and liquid membranes [13] have been widely used. Recently a new liquid-liquid microextraction method based on solidification 
of floating organic drop which was successfully used for the extraction and determination of lead, cooper, palladium, cobalt, and nickel was reported [14-17]. In this method, small volume of an organic solvent with a melting point near room temperature (in the range of $10-30^{\circ} \mathrm{C}$ ) was floated on the surface of aqueous solution. The aqueous phase was stirred for a prescribed period of time, and then the sample was transferred into the ice bath. When the organic solvent was solidified, it was transferred into a small conical vial, and the melted organic solvent was used for analytes determination. The proposed method is very simple and inexpensive. In this method the enrichment factor is higher than the reported methods such as solid phase extraction, liquid-liquid extraction, and cloud point extraction. The LOD of this method is lower, and the extraction time of this method is shorter than that of the other methods mentioned above. In addition, this method uses less toxic organic solvent and it is one of the most important advantages of this method [18]. In this study we consider the possibility of implementation of ultrasound-assisted emulsification microextraction based on solidification floating organic drop (USA-EME-SFO) in combination with graphite furnace atomic absorption spectrometry (GFAAS) in trace manganese analysis. The applicability of the approach was demonstrated for the determination of manganese in water samples. The influence of different experimental parameters on the recovery of the extraction, such as solution $\mathrm{pH}$, chelating agent amount, volume of extraction solvent, and salt effect was described and discussed. Operation simplicity, rapidity, short extraction time, using less amount of toxic organic solvent, and high enrichment factor are some of the USA-EME-SFO advantages.

\section{Experimental}

2.1. Instrumentation. A SpectrAA 220 atomic absorption spectrometer equipped with a graphite furnace atomizer (GTA-110 series) and manganese hollow cathode lamp were used for absorbance measurements at wavelength of $279.5 \mathrm{~nm}$ according to instrument instruction. The instrumental parameters were adjusted according to the manufacturer's recommendations. The sample injection volume was $10.0 \mu \mathrm{L}$ in all experiments. The $\mathrm{pH}$ values were measured with a Metrohm pH meter (Model: 692 Metrohm, Switzerland), supplied with a glass-combined electrode. A NAPCO 2028R Centrifuge was used for centrifugation. An ultrasonic bath system (Model: Tecna 6, Italy) was used for cloudy mixture formation. All $10.0 \mathrm{~mL}$ screw cap falcon test tubes were maintained into $0.1 \mathrm{~mol} \mathrm{~L}^{-1} \mathrm{HNO}_{3}$ for cleaning any inorganic compounds and washed with deionized water and then with acetone for proper sedimentation of fine droplets of the extraction solvent in the centrifugation step.

2.2. Reagents and Solutions. Ultrapure water was used throughout the work. 2-(5-Bromo-2-pyridylazo)-5 diethylaminophenol (5-Br-PADAP) and 1-undecanol were from Merck company (Darmstadt, Germany). Water samples were filtered through $0.45 \mu \mathrm{m}$ membrane filters (Millipore), and then $\mathrm{pH}$ of these samples was adjusted to 10.0 with $\mathrm{NH}_{4} \mathrm{Cl} / \mathrm{NH}_{3}$ buffer $(\mathrm{pH} \sim 10)$. The stock standard solution for $\mathrm{Mn}$ was prepared immediately before use, by stepwise dilution of $1000.0 \mu \mathrm{g} \mathrm{mL}^{-1} \mathrm{Mn}$ (II) stock standard solution in $\mathrm{HNO}_{3} 0.5 \mathrm{~mol} \mathrm{~L}^{-1}$.

2.3. Sample Preparation. Sea, rain, river, and tap water samples were collected in acid-leached polyethylene vials. Acidification to $\mathrm{pH} 1.0$ with nitric acid was performed immediately after collection, in order to prevent adsorption of the manganese ions on the vial walls. The samples were filtered before analyses through a cellulose membrane (Millipore) of $0.45 \mu \mathrm{m}$ pore size.

\subsection{Ultrasound-Assisted Emulsification Microextraction Based on Solidification Floating Organic Drop Procedure. Aliquots of sample solution were placed into a $10 \mathrm{~mL}$ vial, and then $200.0 \mu \mathrm{L}$ of 5 -Br-PADAP $0.05 \%$ and $0.8 \mathrm{~mL} \mathrm{NaCl} 10 \%$ were added to it as a chelating agent and salt, respectively. The solution diluted to $8 \mathrm{~mL}$, and solution $\mathrm{pH}$ adjusted at 10.0 with $\mathrm{NH}_{4} \mathrm{Cl} / \mathrm{NH}_{3}$ buffer. Then $50.0 \mu \mathrm{L}$ of 1 -undecanol was injected to the solution using a $1.0 \mathrm{~mL}$ microsyringe. The sample solution was sonicated for $5 \mathrm{~min}$ until the cloudy mixture was formed. Then the mixture was centrifuged at $6000 \mathrm{rpm}$ for $10 \mathrm{~min}$. Finally vial was transferred into an ice bath. The solidified organic solvent was transferred into the conical vial. After melting the solvent, $10.0 \mu \mathrm{L}$ of this melted solvent was injected into the GFAAS for quantification.}

\section{Results and Discussion}

3.1. Optimization of Furnace Temperature Program. Preliminary studies of the behavior in GFAAS of an extract of standard solution with the temperature program recommended by manufacturers demonstrated that the magnitude of background signal was high. In order to reduce the background without losing the manganese, the temperature program of the furnace was optimized, and the final results are given in Table 1. Under these conditions the background is low and manganese peak has a normal shape.

3.2. Effect of $p H$. The $\mathrm{pH}$ plays a unique role on metalchelate formation and subsequent extraction. So the effect of $\mathrm{pH}$ on the USA-EME-SFO of Mn (II) was studied in the $\mathrm{pH}$ range of 1.0-10.9 using nitric acid and sodium hydroxide with keeping the other variables constant. The results demonstrated that the recovery is nearly constant in the $\mathrm{pH}$ range of 9.2-10.5, so $\mathrm{pH} 10.0$ was selected for further experiments.

3.3. Effect of Chelating Agent Amount. The influence of the amount of 5-Br-PADAP was also evaluated, and the results showed that the maximum recovery is obtained with $200 \mu \mathrm{L}$ of $0.05 \%$ 5-Br-PADAP solution.

3.4. Nature and Volume of Extraction Solvent Effect. The organic solvent used as the extraction solvent in this method should satisfy several criteria: (1) it should have lower density 
TABLE 1: Temperature program of GFAAS for determination of manganese.

\begin{tabular}{lcccc}
\hline Steps & Temperature $\left({ }^{\circ} \mathrm{C}\right)$ & Time $(\mathrm{S})$ & Argon flow rate $\left(\mathrm{L} \mathrm{min}^{-1}\right)$ & Read command \\
\hline Dry stage & 85 & 5.0 & 3.0 & 3.0 \\
Dry stage & 95 & 40.0 & 3.0 & No \\
Dry stage & 270 & 10.0 & 3.0 & No \\
Ash stage & 700 & 5.0 & 3.0 & No \\
Ash stage & 700 & 1.0 & 0.0 & No \\
Gas stop step & 700 & 2.0 & 0.0 & No \\
Ramp step and read command & 2400 & 1.1 & 0.0 & Yes \\
Atomize hold step and read command & 2400 & 2.0 & 3.0 & Yes \\
Tube clean with maximum gas flow & 2430 & 2.0 & & No \\
\hline
\end{tabular}

than water; (2) it should be low volatile to prevent loss of the solvent during the extraction process; (3) it should provide an appropriate extraction efficiency to provide high extraction recoveries and thus high enrichment factor; (4) its melting point should be near the room temperature $\left(10-30^{\circ} \mathrm{C}\right)$ [24]. Accordingly, several extraction solvents such as 1-undecanol, 1-dodecanol, and 2-dodecanol were investigated. Based on the obtained results, 1-undecanol had the best extraction efficiency. Also because of its low vapor pressure at the extraction conditions, the extract was stable at the extraction period. Therefore, 1-undecanol was selected as the extraction solvent. The effect of extraction solvent volumes on the recovery was determined, in the range of $30.0-90.0 \mu \mathrm{L}$. Results showed that $50.0 \mu \mathrm{L}$ is the optimum volume of 1-undecanol.

3.5. Effect of Extraction Time. The influence of the extraction time was examined in the experimental conditions. In USAEME-SFO, extraction time is defined as the time interval between injecting of the extraction solvent and starting to centrifuge. The results displayed that the extraction time had no notable effect on the recovery of extraction, so $5 \mathrm{~min}$ was selected as an extraction time in this procedure.

3.6. Salt Effect. For investigating the influence of the ionic strength on the USA-EME-SFO performance, several experiments were performed by adding different kinds of salt, such as $\mathrm{KI}, \mathrm{NaCl}$, and $\mathrm{NaNO}_{3}$. The recoveries were $75.8 \%$, $98.6 \%$, and $62.1 \%$ for $\mathrm{KI}, \mathrm{NaCl}$, and $\mathrm{NaNO}_{3}$, respectively. $\mathrm{NaCl}$ was selected for subsequent experiments. The effect of the amount of $\mathrm{NaCl}$ on the extraction efficiency was studied with different amount of $\mathrm{NaCl}$ in the range of $0.01-0.3 \mathrm{~g}$ $\mathrm{NaCl}$.

3.7. Effect of Diverse Ions. Various salts and metal ions were added to a solution containing $3.0 \mathrm{ng} \mathrm{mL}^{-1}$ of Mn (II) ions, and the general procedure was applied. The results (error $< \pm 5 \%$ ) are given in Table 2 . most of the metal ions that were studied did not interfere higher than $500 \mathrm{~mol}$ ratio level. Thus the method is selective and may safely be applied for the determination of manganese in various water samples.
TABLE 2: Effect of diverse ions.

\begin{tabular}{lcc}
\hline Interferent & Interferent/Mn (II) ratio $(\mathrm{mol} / \mathrm{mol})$ & Recovery $(\%)$ \\
\hline $\mathrm{Fe}^{3+}$ & 10000 & 96.3 \\
$\mathrm{Ca}^{2+}, \mathrm{Mg}^{2+}$ & 5000 & 95.9 \\
$\mathrm{Zn}^{2+}$ & 4500 & 97.6 \\
$\mathrm{Cd}^{2+}$ & 2000 & 97.1 \\
$\mathrm{Al}^{3+}$ & 2000 & 96.7 \\
$\mathrm{Ni}^{2+}$ & 1000 & 95.6 \\
$\mathrm{~Pb}^{2+}, \mathrm{Cu}^{2+}$ & 800 & 95.8 \\
$\mathrm{Co}^{2+}$ & 500 & 95.4 \\
\hline
\end{tabular}

3.8. Figures of Merit. Performance characteristics of the method were obtained by processing standard solution of manganese. For a sample volume of $8 \mathrm{~mL}$, the calibration graph exhibited linearity over the range of $0.5-10 \mathrm{ng} \mathrm{mL}-1$ with a correlation coefficient of 0.9926 . The relative standard deviation $(n=8)$ at $3 \mathrm{ng} \mathrm{mL} \mathrm{mL}^{-1}$ was $\pm 3.3 \%$. The enrichment factor for the proposed method was 160, as obtained from the ratio of the volume of the aqueous phase to organic phase. The limit of detection, based on two times the standard deviation of the blank signal divided by the slop of the calibration curve, was $0.3 \mathrm{ng} \mathrm{mL}^{-1}$.

3.9. Water Analysis. The proposed method was applied to the determination of Mn (II) in different water samples, and the results along with the recovery for the spiked samples were given in Table 3. As could be seen, the recoveries for the three spiked water samples were in the range of $97.5-105 \%$.

3.10. Comparison of USA-EME-SFO with Other Methods. A comparison of the represented method with other reported preconcentration methods of Mn (II) is given in Table 4. As can be seen, the present method has higher enrichment factor than other methods such as cloud point extraction (CPE) [19], single-drop microextraction (SDME) [20], and dispersive liquid-liquid microextraction (DLLME) [21]. This method also has a lower limit of detection than CPE [19], 
TABLE 3: Determination of manganese in the water samples.

\begin{tabular}{|c|c|c|c|}
\hline Sample & Spiked (ng mL $\left.{ }^{-1}\right)$ & Found $^{\mathrm{a}}\left(\mathrm{ng} \mathrm{mL}^{-1}\right)$ & Recovery (\%) \\
\hline Sea water (Persian gulf) & $\begin{array}{l}0.00 \\
0.20\end{array}$ & $\begin{array}{l}7.60 \pm 0.32 \\
7.79 \pm 0.28\end{array}$ & $\overline{95.0}$ \\
\hline Rain water (Kerman) & $\begin{array}{l}0.00 \\
0.70\end{array}$ & $\begin{array}{c}\text { No detect } \\
0.74 \pm 0.03\end{array}$ & $\overline{105.7}$ \\
\hline Tap water (Tehran) & $\begin{array}{l}0.00 \\
0.20\end{array}$ & $\begin{array}{l}5.24 \pm 0.21 \\
5.45 \pm 0.24\end{array}$ & $\overline{105.0}$ \\
\hline Tap water (Kerman) & $\begin{array}{l}0.00 \\
0.30\end{array}$ & $\begin{array}{l}1.94 \pm 0.07 \\
2.23 \pm 0.08\end{array}$ & $\overline{96.6}$ \\
\hline River water (Esfahan) & $\begin{array}{l}0.00 \\
0.60 \\
\end{array}$ & $\begin{array}{l}3.28 \\
3.90 \\
\end{array}$ & $\overline{103.3}$ \\
\hline
\end{tabular}

${ }^{\mathrm{a}}$ Mean \pm Standard deviation $(n=3)$.

TABLE 4: Comparison of the USA-EME-SFO with other methods for extraction and determination of manganese.

\begin{tabular}{lccc}
\hline Method & Enrichment factor & LOD $\left(\mathrm{ng} \cdot \mathrm{mL}^{-1}\right)$ & Reference \\
\hline $\begin{array}{l}\text { LLE using water-in-oil } \\
\text { emulsion-AAS }\end{array}$ & 820 & 0.02 & {$[1.4$} \\
CPE-FAAS & 20 & 0.02 & {$[19]$} \\
SDME-ETAAS & 30.3 & 0.5 & {$[20]$} \\
DLLME-FAAS & 82.6 & 5 & {$[21]$} \\
SPE-FAAS & - & 0.5 & {$[22]$} \\
LL-USAEME-FAAS & - & 0.30 & {$[23]$} \\
USA-DLLME-SFO-GFAAS & 160 & & This work \\
\hline
\end{tabular}

solid phase extraction (SPE) [22], ligandless-ultrasoundassisted emulsification microextraction (LL-USAEME) [23], and DLLME [21] methods. Thus it is suitable for ultra trace analysis of manganese in aqueous samples.

\section{Conclusions}

This paper outlines a successful development and application of the USA-EME-SFO technique, combined with the GFAAS, for trace determination of manganese in several categories of water samples. Compared with other conventional sample preparation methods, the analytical technique offered numerous advantages such as simplicity, low cost, ease of operation, rapid analysis time, and reproducible and high enrichment factor and is suitable for determining manganese in different water samples. The extraction solvent (1Undecanol) of this method has lower toxicity than DLLME, and thus this method is more environmental friendly.

\section{References}

[1] R. M. Leach and M. S. Lilburn, "Manganese in enteral and parenteral nutrition," World Review of Nutrition and Dietetics, vol. 32, pp. 123-134, 1989.

[2] C. L. Keen and R. M. Leach, "Manganese," in Chapter 34 in Handbook on Toxicity of Inorganic Compounds, H. S. Seiler and H. Sigel, Eds., Marcel Dekker, New York, NY, USA, 1987.

[3] J. I. Drever, The Geochemistry of Natural Waters, Prentice-Hall, New Jersey, NJ, US, 3rd edition, 1997.

[4] W. Davison, "Iron and manganese in lakes," Earth Science Reviews, vol. 34, no. 2, pp. 119-163, 1993.
[5] M. Okumura, T. Anate, K. Fujinaga, and Y. Seike, "A simple and rapid in situ preconcentration method using solid-phase extraction for the determination of dissolved Manganese in brackish lake water samples," Analytical Sciences, vol. 18, no. 10, pp. 1093-1097, 2002.

[6] M. Doğutan, H. Filik, and R. Apak, "Preconcentration of manganese(II) from natural and sea water on a palmitoyl quinolin-8-ol functionalized XAD copolymer resin and spectrophotometric determination with the formaldoxime reagent," Analytica Chimica Acta, vol. 485, no. 2, pp. 205-212, 2003.

[7] F. Gode and E. Pehlivan, "A comparative study of two chelating ion-exchange resins for the removal of chromium(III) from aqueous solution," Journal of Hazardous Materials, vol. 100, no. 1-3, pp. 231-243, 2003.

[8] A. Ersöz, R. Say, and A. Denizli, "Ni(II) ion-imprinted solidphase extraction and preconcentration in aqueous solutions by packed-bed columns," Analytica Chimica Acta, vol. 502, no. 1, pp. 91-97, 2004.

[9] S. Baytak and A. R. Türker, "Flame atomic absorption spectrometric determination of manganese in alloys after preconcentration onto amberlite XAD-4 loaded with Saccharomyces carlsbergensis," Turkish Journal of Chemistry, vol. 28, no. 2, pp. 243-253, 2004.

[10] A. M. Starvin and T. P. Rao, "Removal and recovery of mercury(II) from hazardous wastes using 1-(2-thiazolylazo)2-naphthol functionalized activated carbon as solid phase extractant," Journal of Hazardous Materials, vol. 113, no. 1-3, pp. 75-79, 2004.

[11] Y. Okamoto, Y. Nomura, H. Nakamura, K. Iwamaru, T. Fujiwara, and T. Kumamaru, "High preconcentration of ultra-trace metal ions by liquid-liquid extraction using 
water/oil/water emulsions as liquid surfactant membranes," Microchemical Journal, vol. 65, no. 3, pp. 341-346, 2000.

[12] V. O. Doroschuk, S. O. Lelyushok, V. B. Ishchenko, and S. A. Kulichenko, "Flame atomic absorption determination of manganese(II) in natural water after cloud point extraction," Talanta, vol. 64, no. 4, pp. 853-856, 2004.

[13] L. Soko, L. Chimuka, E. Cukrowska, and S. Pole, "Extraction and preconcentration of manganese(II) from biological fluids (water, milk and blood serum) using supported liquid membrane and membrane probe methods," Analytica Chimica Acta, vol. 485, no. 1, pp. 25-35, 2003.

[14] S. Dadfarnia, A. M. Salmanzadeh, and A. M. H. Shabani, "A novel separation/preconcentration system based on solidification of floating organic drop microextraction for determination of lead by graphite furnace atomic absorption spectrometry," Analytica Chimica Acta, vol. 623, no. 2, pp. 163-167, 2008.

[15] C. X. Wu, Q. H. Wu, C. Wang, and Z. Wang, "A novel method for the determination of trace copper in cereals by dispersive liquid-liquid microextraction based on solidification of floating organic drop coupled with flame atomic absorption spectrometry," Chinese Chemical Letters, vol. 22, no. 4, pp. 473-476, 2011.

[16] M. Mohamadi and A. Mostafavi, "A novel solidified floating organic drop microextraction based on ultrasound-dispersion for separation and preconcentration of palladium in aqueous samples," Talanta, vol. 81, no. 1-2, pp. 309-313, 2010.

[17] M. S. Bidabadi, S. Dadfarnia, and A. M. H. Shabani, "Solidified floating organic drop microextraction (SFODME) for simultaneous separation/preconcentration and determination of cobalt and nickel by graphite furnace atomic absorption spectrometry (GFAAS)," Journal of Hazardous Materials, vol. 166, no. 1, pp. 291-296, 2009.

[18] M. I. Leong and S. D. Huang, "Dispersive liquid-liquid microextraction method based on solidification of floating organic drop for extraction of organochlorine pesticides in water samples," Journal of Chromatography A, vol. 1216, no. 45, pp. 7645-7650, 2009.

[19] Z. Sun, P. Liang, Q. Ding, and J. Cao, "Cloud point extraction preconcentration of manganese(II) from natural water samples using 1-phenyl-3-methyl-4-benzoyl-5-pyrazolone and triton X-100 and determination by flame atomic absorption spectrometry," Analytical Sciences, vol. 22, no. 6, pp. 911-913, 2006.

[20] J. L. Manzoori, M. Amjadi, and J. Abulhassani, "Ionic liquidbased single drop microextraction combined with electrothermal atomic absorption spectrometry for the determination of manganese in water samples," Talanta, vol. 77, no. 4, pp. 15391544, 2009.

[21] R. Khani and F. Shemirani, "Determination of trace levels of Nickel and Manganese in soil, vegetable, and water," CleanSoil, Air, Water, vol. 38, no. 12, pp. 1177-1183, 2010.

[22] A. P. dos Anjos, L. Cornejo-Ponce, S. Cadore, and N. Baccan, "Determination of manganese by flame atomic absorption spectrometry after its adsorption onto naphthalene modified with 1-(2-pyridylazo)-2-naphthol (PAN)," Talanta, vol. 71, no. 3, pp. 1252-1256, 2007.

[23] S. Z. Mohammadi, D. Afzali, Y. M. Baghelani, and L. Karimzadeh, "Ultrasound-assisted emulsification microextraction of trace amounts of $\mathrm{Co}$ and $\mathrm{Mn}$ ions prior to flame atomic absorption spectrometry," Journal of the Brazilian Chemical Society, vol. 22, no. 1, pp. 104-110, 2011.
[24] H. R. Sobhi, Y. Yamini, A. Esrafili, and R. H. H. B. Abadi, "Suitable conditions for liquid-phase microextraction using solidification of a floating drop for extraction of fat-soluble vitamins established using an orthogonal array experimental design," Journal of Chromatography A, vol. 1196-1197, no. 1-2, pp. 28-32, 2008. 


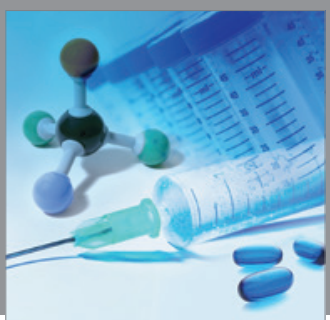

International Journal of

Medicinal Chemistry

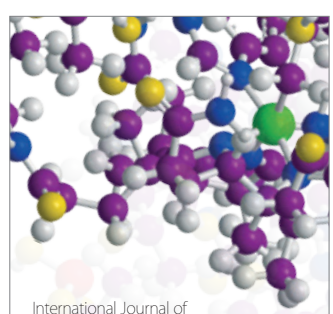

Carbohydrate Chemistry

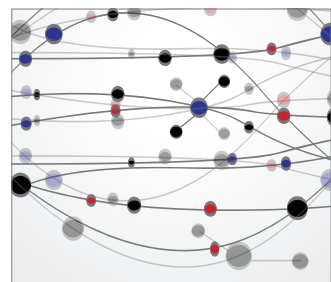

The Scientific World Journal
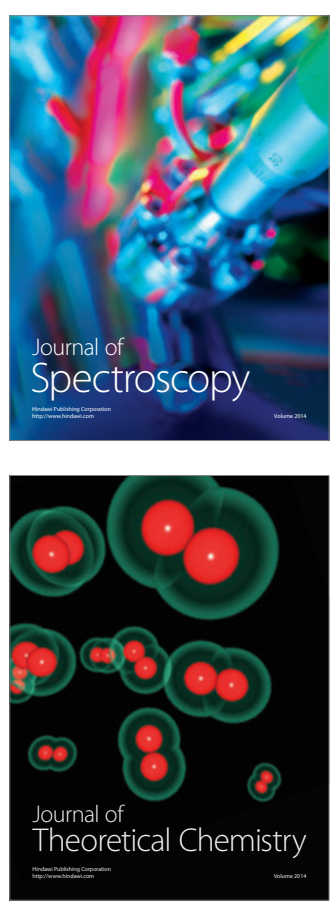
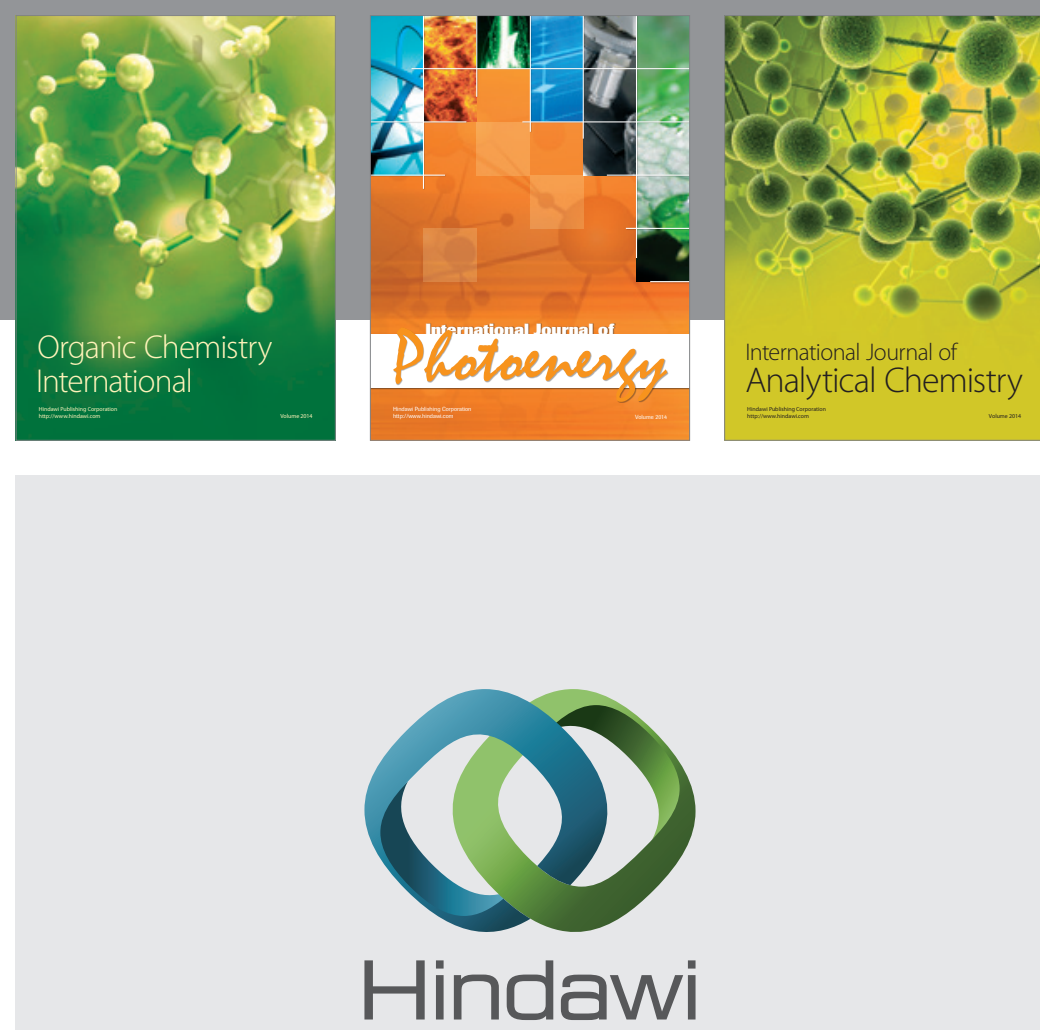

Submit your manuscripts at

http://www.hindawi.com
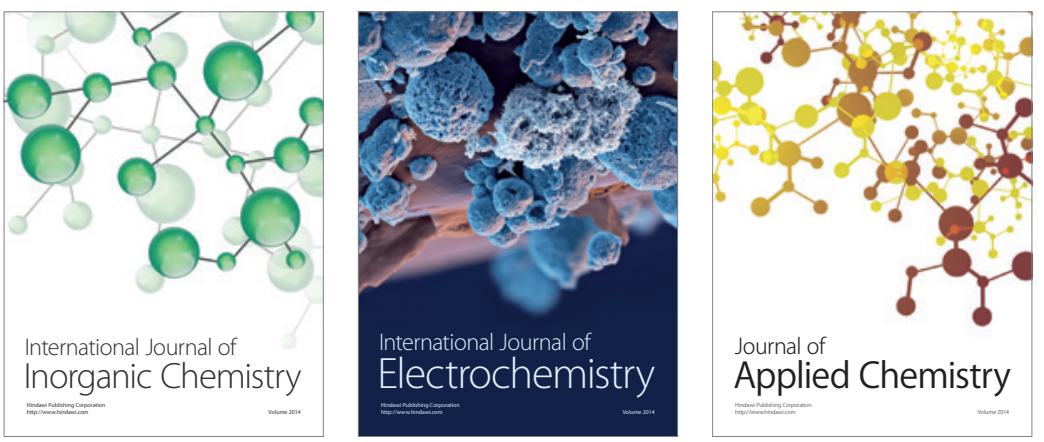

Journal of

Applied Chemistry
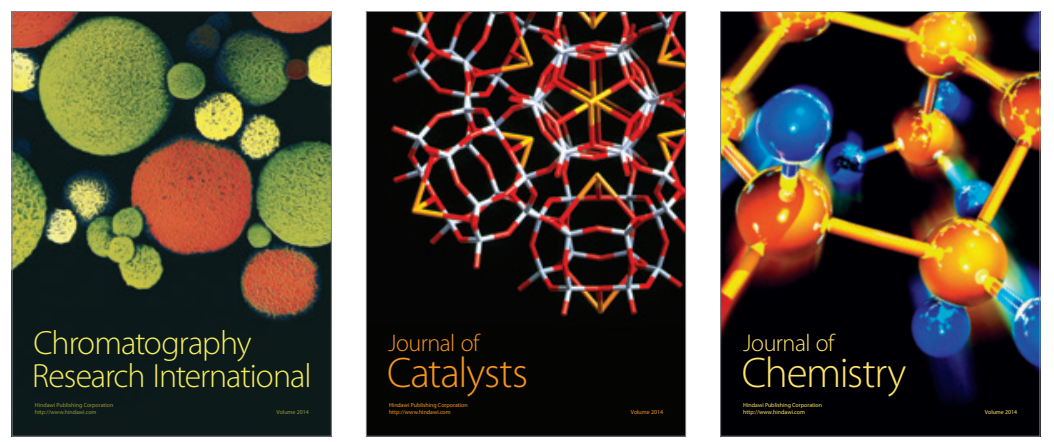
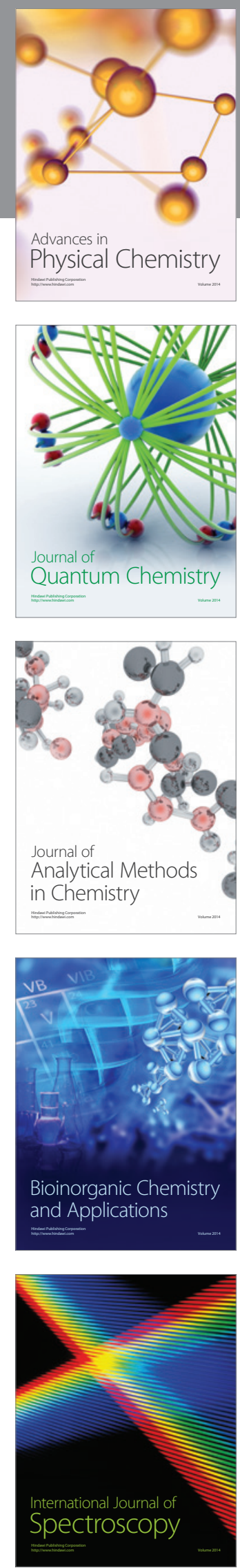